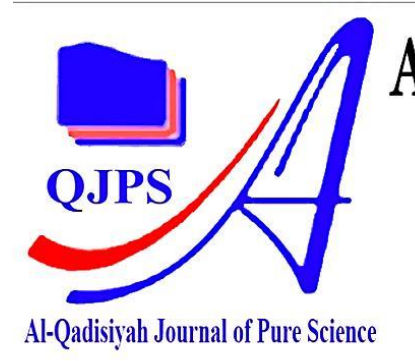

Al-Qadisiyah Journal of Pure Science

ISSN(Printed): 1997-2490

ISSN(Online):

$2411-3514$

DOI : /10.29350/jops.

http://qu.edu.iq/journalsc/index.php/JOPS

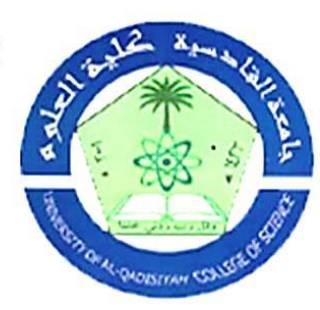

\title{
Isolation and Identification of Several Bacteria from Oral Cavity among Humans in Soran City
}

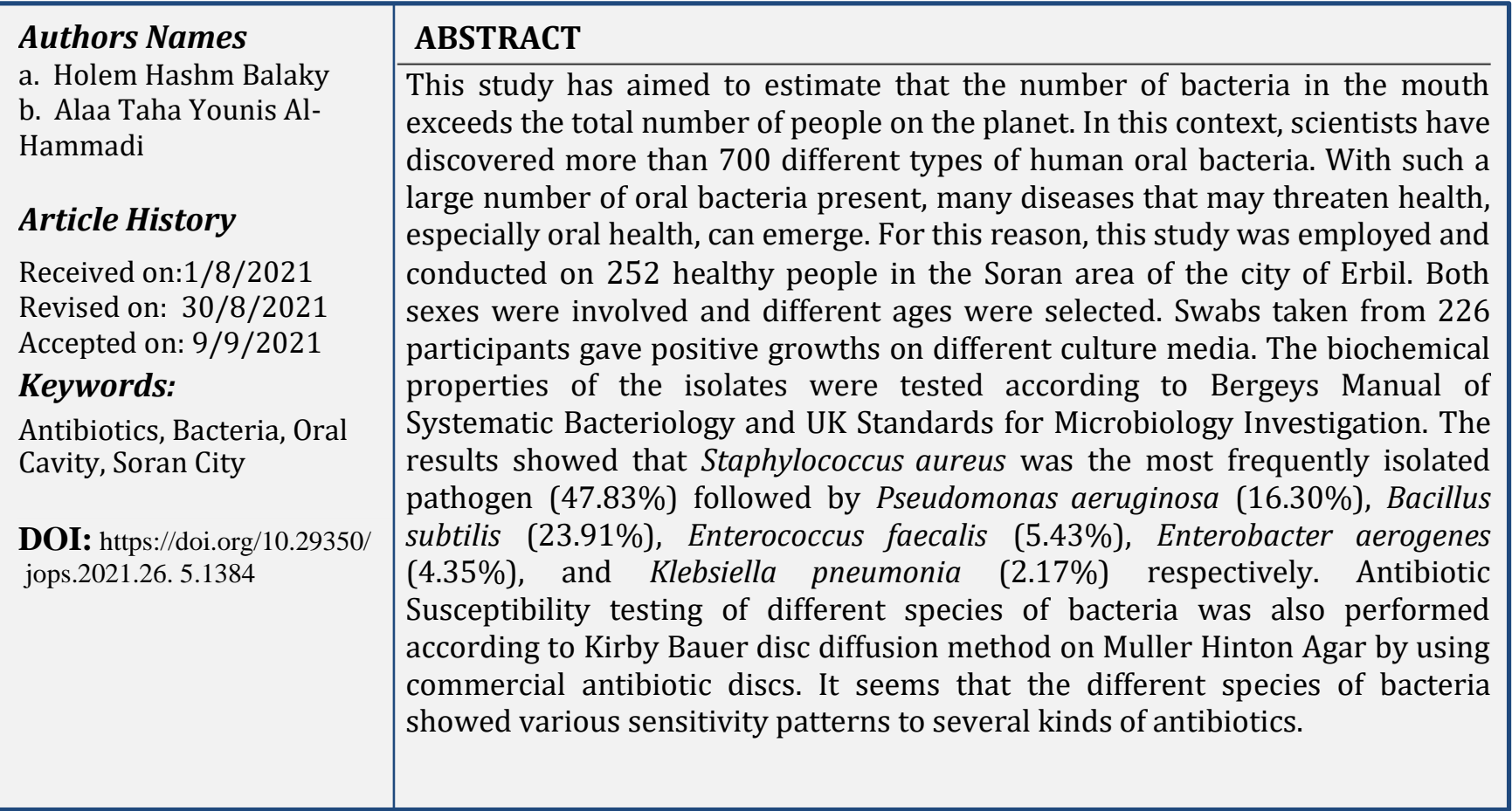

\section{Introduction}

The oral cavity is the only major passage to the internal human body, food passes through the oral cavity to the digestive system, air also passes through the nostrils, and the oral cavity to the respiratory tract. This creates a continuous channel and could cause microorganisms colonizing one area of the oral cavity to have a significant probability of spreading on other neighboring sites. The presence of Saccharomyces species and Candida has been found to correlate with the severity of hepatitis, pneumonia, cardiovascular diseases, and other systemic diseases (Dolnicar and Chapple 2015).

Also, The oral cavity provides two types of surfaces for bacteria colonization - soft tissue and hard tooth enamel/exposed root surfaces - thus supporting the growth of different bacterial

\footnotetext{
a General Science Department, Faculty of Education, Soran University, Erbil, Kurdistan-Iraq, E-Mail: holem86@gmail.com

a Kahramanmaraş Sütçü İmam University, Department of Bioengineering and Sciences, Turkey, Iraq, holem.rasul@gsci.soran.edu.iq

b Department of Microbiology, College of Education for Pure Science, University of Mosul, Mosul, Iraq, E-Mail:

alaatyounis@uomosul.edu.iq
} 
communities(Marcotte and Lavoie 1998) (Press et al. 2004). Because the microorganisms present in saliva are removed from different surfaces of the mouth, saliva flora can provide an overview of the bacteria in the mouth of an individual (Press et al. 2004)

It is known worldwide that the Staphylococcus spp. and Candida spp., are recognized to be probable pathogens in patients with various systemic debilitations, such as diabetes, neutropenia, agranulocytosis, and AIDS (Cuesta et al. 2010). Although Staphylococci is assumed to be a transient resident in the oral cavity (Ohara-Nemoto et al. 2008), it is suspected of being a pathogen in a variety of oral diseases, including dental caries (Petti et al. 2014).

The goal of the study was to determine the most pathogenic bacteria species in the oral cavity of healthy males and females. Mouth rinses containing antimicrobial agents exert beneficial clinical effects when used as adjuncts in treating periodontal disease. Antibacterial activities and the effectiveness in reducing or retarding plaque formation were comprehensively studied (Barkvoll and Attramadal 1989)

\section{MATERIAL METHODS}

\subsection{Test on the antibiotic activity of Oral rinse technique}

\subsubsection{Bacteria Oral rinse}

The oral cavity in healthy subjects has a well-balanced macrobiotic that consists of approximately 1.0 $\times 10^{11}$ microbes/g of dental plaque, and more than 700 species reside on the tongue dorsum, buccal epithelium, hard and soft palates, and other surfaces (Aas et al. 2005), some studies have demonstrated that a disturbance of this balance, with an increase of harmful microbes and a decrease of beneficial microbes, causes oral disorders, such as periodontal disease and dental caries (Duran-Pinedo et al. 2014).

\subsubsection{Sample Collection and study area}

In this study, 226 samples gave a positive result for growth out of a total of 352 collected from Hospital by toothpicks $0.1 \mathrm{ml}$ of suspension was cultivated by spread plate method on each blood agar, mannitol agar, McConkey agar. Then, the dishes were incubated in aerobic conditions at $37{ }^{\circ} \mathrm{C}$ for 24 48 hours. After incubation, the colonies were counted and the developing bacteria were diagnosed using Macfaddin (2000) (Medicine 1984) (Patricia M.Tille 2015).

\subsubsection{Effect of antibiotics on bacterial isolates}

Antibiotic disk diffusion test depends on measuring the growth inhibition zone around antibiotic disks and comparing it with these reported by Clinical and Laboratory Standards Institution (CLSI) guidelines[12,13]. Rely on the standard (Kirby - Bauer method) as mentioned in Mueller-Hinton agar medium was inoculated with the young suspension of bacteria using a sterile cotton swab. Then the following antibiotic tablets were distributed Penicillin G: P10 $\mu$, Ampicillin AMP10 $\mu$, Tetracycline:

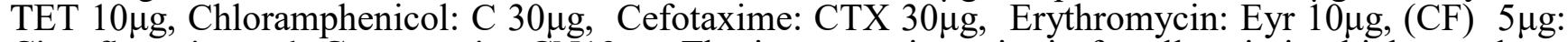
Ciprofloxacin, and, Gentamycin: CN10 $\mu$ g. The interpretative criteria for all antimicrobials are those recommended by the National Committee on Infectious Diseases and Diseases (Turnbull et al. 2004).

\section{RESULTS AND DISCUSSION}

This in vitro study to assess the antibacterial activities was carried out using oral cavity assays. this study included (252) samples were collected from 226 participants who gave positive growths on different culture media. by plaque and swab samples from the oral cavity without any patients, such as bad smell, no smoking, regular teeth brushing, and prevent of soda pop consumption. The total of 252 
samples divided to gender ranges from male (150) sample with gender ranges from female 102 samples with the positive and negative culture of results.

However, a total of (252) Thus, the positive culture from male was $88 \%$, and female was $91 \%$ with the negative culture from male $13 \%$, and female $8 \%$ respectively shown Table 1, and Figure 1.

Table 1: Distribution of human pathogen with an oral cavity in human

\begin{tabular}{lllllll}
\hline & Male & \multicolumn{3}{c}{ Female } & \multicolumn{2}{c}{ Average (Male and Female) } \\
\hline Culture results & No. & $\%$ & No. & $\%$ & No & $\%$ \\
\hline Positive Culture & 126 & $\mathbf{8 8 \%}$ & 91 & $91 \%$ & 217 & 89.5 \\
Negative Culture & 24 & $13 \%$ & 11 & $8 \%$ & 35 & 10.5 \\
Total & 150 & $65 \%$ & 102 & $35 \%$ & 252 & 100 \\
\hline
\end{tabular}

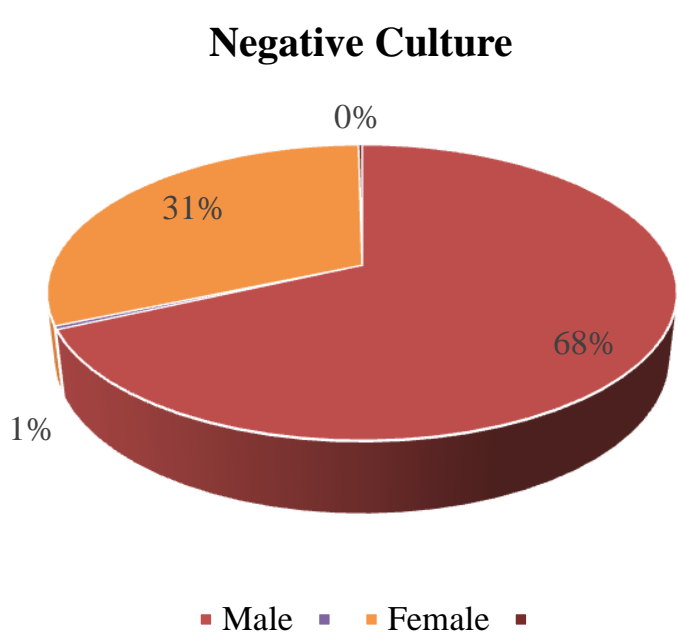

Figure 1: Distribution of human pathogen with an oral cavity in Male and Female

The present study compares favorably with investigations by the antibiotic. six oral mucosal bacterial species were identified from the oral cavity of 252 people, in decreasing order of dominance; Staphylococcus aureus (47.83\%), Pseudomonas aeruginosa (23.91\%), Bacillus subtilis (5.43\%), Enterococcus faecalis (4.34\%), Enterobacter aerogenes (2.17\%), and Klebsiella pneumonia (0.85\%), but all total of bacteria species were isolated 92 shown Table 2, and Figure 2. Therefore, the results were shown that the gram-positive bacterial isolates were the most abundant (71.74\%). the Staphylococcus aureus more common isolates from male and female as value (47.83\%), followed by Bacillus subtilis (23.91\%), while the Gram-negative bacterial isolates recorded (28.24\%) as shown in Table 2. his group of the (Hua Xie et al. 2000), and (Y Li, Y Ge 2007), confirmed that Gram-positive bacteria are prevalent in adults and children and that Staphylococcus bacteria is the most common, and this is spent with (Al-Abdul AA 2017) (Lateef and Ibrahim 2017). Because it has surface antigens and degrading enzymes that help it penetrate different body tissues. However, the bacteria negative-gram 
was lower than the gram-positive bacteria. According to several studies, most gram-negative bacteria originate from inflammation of the respiratory tract and the gastrointestinal tract.

Table 2: incidence of all bacteria isolated in male and female culture from the oral cavity

\begin{tabular}{clcc}
\hline Bacteria code. & \multicolumn{1}{c}{ Bacteria species } & Isolated & Percentage (\%) \\
\hline B 1 & Staphylococcus aureus & 44 & $47.83 \%$ \\
\hline B2 & Pseudomonas aeruginosa & 15 & $16.30 \%$ \\
\hline B3 & Bacillus subtilis & 22 & $23.91 \%$ \\
\hline B4 & Enterococcus faecalis & 5 & $5.43 \%$ \\
\hline B5 & Enterobacter aerogenes & 4 & $4.34 \%$ \\
\hline B6 & Klebsiella pneumonia & 2 & $2.17 \%$ \\
\hline Total & Total of bacteria species were isolated & 92 & \\
\hline
\end{tabular}

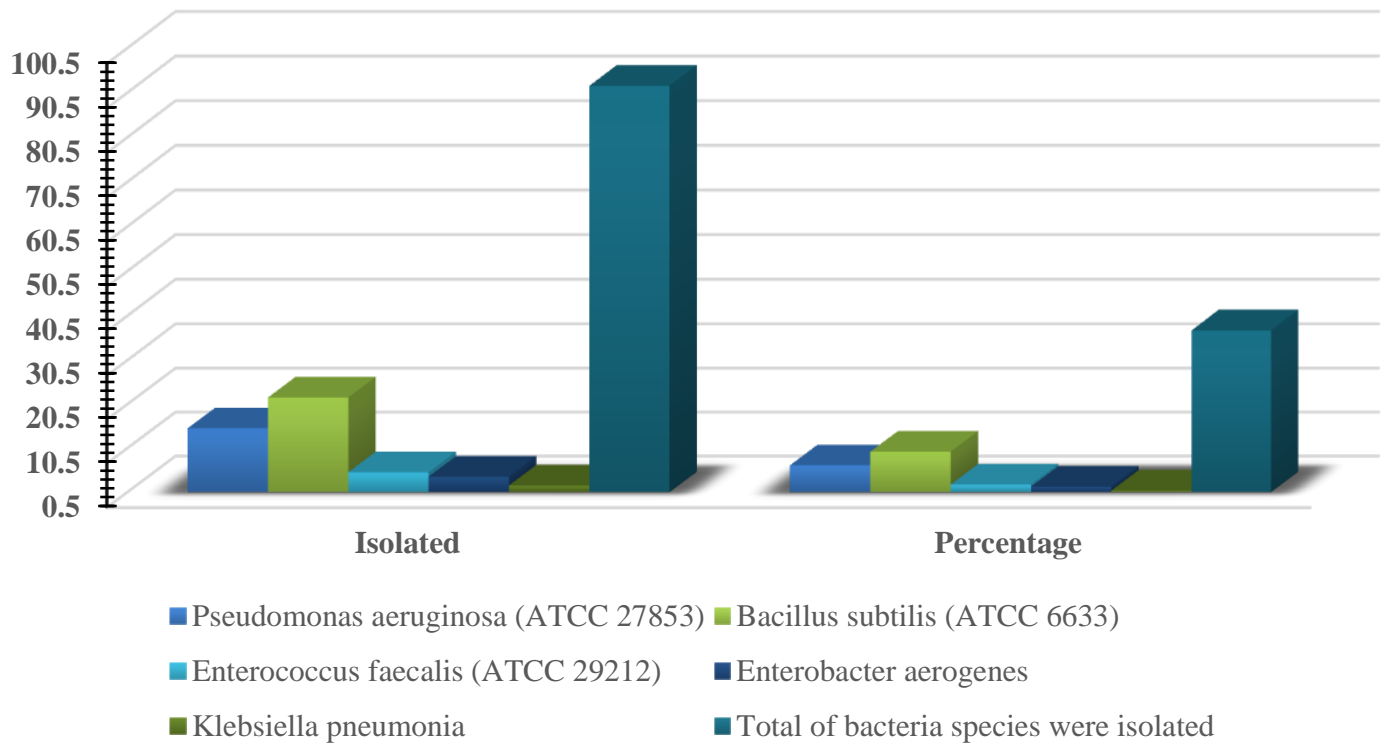

Figure 2: incidence of all bacteria isolated from the oral cavity

Many studies were conducted to Identification and Isolation bacteria from the oral cavity, that the amounts and types of microorganisms found in the oral cavity may vary among individuals with different males and females. Also, there are many bacteria inhibited by some antibacterial agents. Furthermore, the inhibition zone significantly was seen in (Table 3).and (Figure 4), the antibacterial activities of the treatment of oral cavity by synthetic antibacterial discs used positive control as P10, AMP10, TE10, (Ch)C30, (Ce)CTX30, Eyr10, (Ci)CPR5, and (Ge)CN10. Furthermore. the topmost antibacterial values ranged between in (Ch)C30 (13.70 -28.49), and (Ce)CTX30 (26.80-29.53) respectively, as significant by the diameters of inhibition zones of most the activities against the organism's test, whereas the inhibition zone ranged from 7.80 to $29.53 \mathrm{~mm}$ against all bacteria tests. Also, the highest antibacterial activity was seen against the Staphylococcus aureus and Klebsiella pneumonia at all diameter zone of antibacterial activity respectively. Therefore, among all bacteria, just five artificial antibacterial were significantly affected against the growth of microorganisms. 
On the other hand, all the studied microorganisms seem to be resistant to Cefotaxime, Tetracycline, cephalosporin, and Chloramphenicol, respectively. This resistance might be attributed to the beta-lactamase production by these microorganisms which destroys the beta-lactam ring of penicillin's and 7- amino cephalosporin acid ring of cephalosporin respectively. Since these rings are the site of antimicrobial activity of these drugs, therefore destruction of these rings renders microorganism's resistant to these antibiotics. These results are expected regarding all six bacteria since all these microorganisms are known to produce beta-lactamase enzymes as indicated in the literature (Ibrahim et al. 2014), (Alaa 2016).

Table 3: Results of Diameter of Antibiotic zone against the oral cavity in micro dilution assay

\begin{tabular}{|l|c|c|c|c|c|c|c|c|}
\hline & \multicolumn{7}{|c|}{ Antibiotic (Antimicrobial Agent) / Susceptible } \\
\hline Bacteria & P10 & AMP10 & TE10 & (Ch)C30 & (Ce)CTX30 & Eyr10 & (Ci)CPR5 & (Ge)CN10 \\
\hline B.1 & 12.94 & 12.83 & 21.73 & 24.70 & 29.53 & 11.60 & 22.76 & 16.90 \\
\hline B.2 & 11.09 & 10.59 & 21.66 & 20.72 & 26.80 & 16.45 & 18.58 & 10.19 \\
\hline B.3 & 14.30 & No & 20.08 & 24.91 & 28.25 & 11.37 & 21.85 & 11.10 \\
\hline B.4 & 8.27 & 7.80 & 22.23 & 13.70 & 26.36 & 13.14 & 21.50 & 10.71 \\
\hline B.5 & 10.02 & 11.42 & 22.37 & 26.13 & 27.48 & 8.80 & 21.29 & 17.66 \\
\hline B.6 & 10.61 & 12.64 & 21.54 & 28.49 & 28.41 & 12.98 & 19.42 & 14.21 \\
\hline
\end{tabular}

I.Z.mm: inhibition zone of Concentration; Bacteria: B.1=Staphylococcus aureus (ATCC 29213), B.2= Pseudomonas aeruginosa (ATCC 27853), B.3= Bacillus subtilis (ATCC 6633), B.4=Enterococcus faecalis (ATCC 29212),B.5=Enterobacter aerogenes, B.6=Klebsiella pneumonia (CCM 2318); Antibiotic (Antimicrobial Agent) / Susceptible: Penicillin G: P10 $\mu \mathrm{g}$, Ampicillin (other) : AMP10 $\mu \mathrm{g}$, Tetracycline : TET $10 \mu \mathrm{g}$, Chloramphenicol : C $30 \mu \mathrm{g}$, Cefotaxime : CTX $30 \mu \mathrm{g}$, Erthromycin : Eyr $10 \mu \mathrm{g}$, (CF) $5 \mu \mathrm{g}$ : Ciprofloxacin, and, Gentamycin : CN10 $\mu \mathrm{g}$; N.D: Not Detected. 


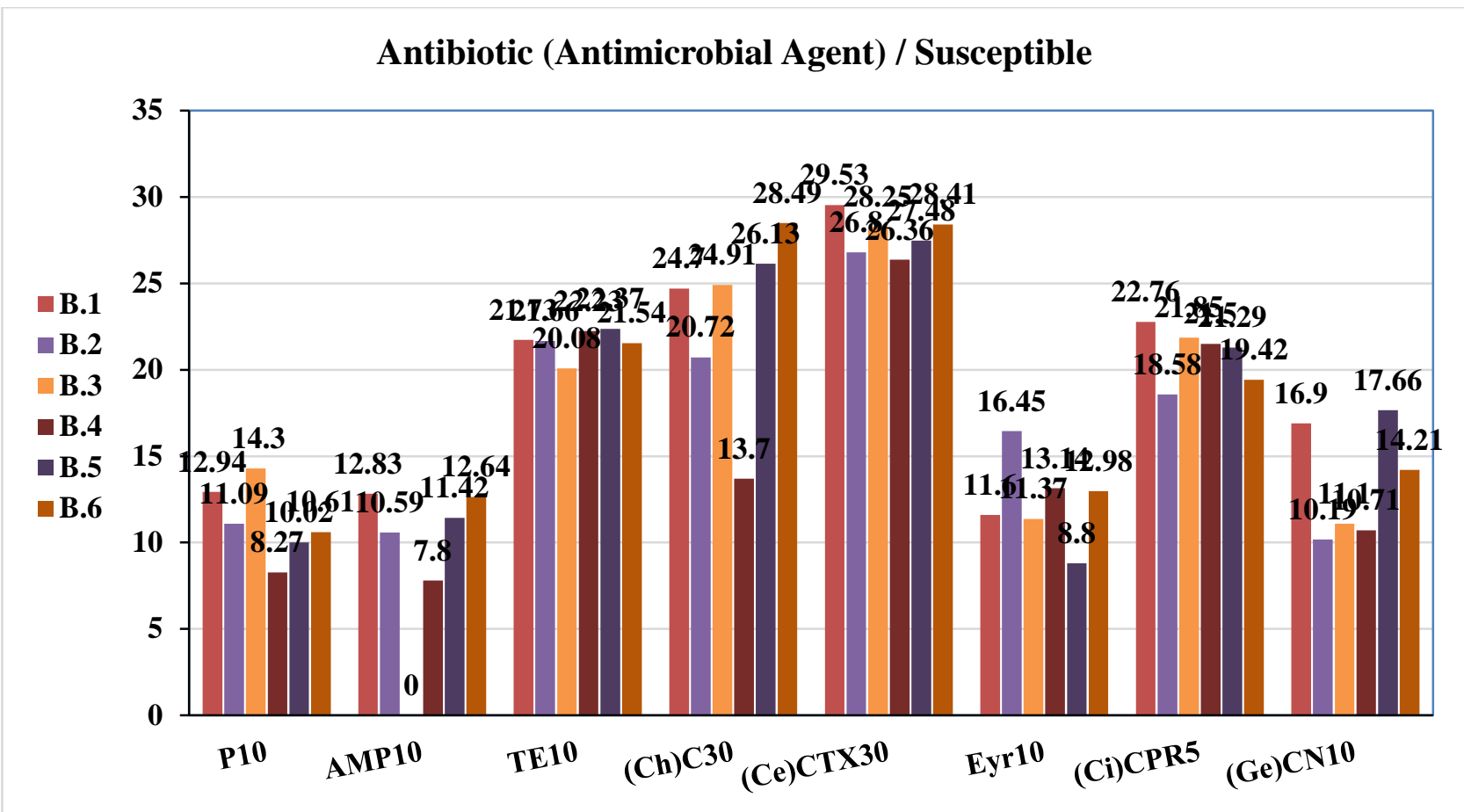

Fig 4: Prevalence of oral bacteria species with antibiotics in human

\section{CONCLUSION}

The positive culture from males was $88 \%$, and females were $91 \%$ with the negative culture from males $13 \%$ and females $8 \%$ respectively. However, the results were showed that the gram-positive bacterial isolates were the most abundant (71.74\%). the Staphylococcus aureus is a more common isolate from males and females as value (47.83\%). On the other hand, the highest antibacterial activity was seen against the Staphylococcus aureus and Klebsiella pneumonia at all diameter zone of antibacterial activity respectively. Therefore, among all bacteria, just five artificial antibacterial were significantly affected against the growth of microorganisms. that the different species of bacteria showed various sensitivity patterns to several kinds of antibiotics.

\section{REFERENCES}

Aas, J.A., Paster, B.J., Stokes, L.N., Olsen, I., and Dewhirst, F.E., 2005. Defining the normal bacterial flora of the oral cavity. Journal of Clinical Microbiology, 43 (11), 5721-5732.

Al-Abdul AA, H.I., 2017. Isolation and Identification of Bacteria from Diabetic and Non-diabetic Patients with Periodontitis. Donn J Microb Biotec Res, 4 (2), 004-009.

Alaa, Y.T., 2016. Comparative Study of Two Beta - Lactamase Test Methods in Five Different Microorganisms Isolated from. International Journal of Scientific and Research Publications, 6 (10), 1-4.

Barkvoll, P. and Attramadal, A., 1989. Effect of nystatin and chlorhexidine digluconate on Candida albicans. Oral Surgery, Oral Medicine, Oral Pathology. 
Cruz, A.B., Cé, R., Cruz, B., Kanegusuku, M., Filho, V.C., Yunes, R.A., Delle Monache, F., and Niero, R., 2006. Antimicrobial activity of Rubus imperialis (Rosaceae). Acta Farm. Bonaerense, 25 (2), 256-259.

Cuesta, A.I., Jewtuchowicz, V., Brusca, M.I., Nastri, M.L., and Rosa, A.C., 2010. Prevalence of Staphylococcus spp and Candida spp in the oral cavity and periodontal pockets of periodontal disease patients. Acta odontológica latinoamericana : AOL, 23 (1), 20-26.

Deliorman Orhan, D., Özçelik, B., Hoşbaş, S., and Vural, M., 2012. Assessment of antioxidant, antibacterial, antimycobacterial, and antifungal activities of some plants used as folk remedies in Turkey against dermatophytes and yeast-like fungi. Turkish Journal of Biology, 36 (6), 672-686.

Dolnicar, S. and Chapple, A., 2015. The human oral microbiome. Annals of Tourism Research.

Duran-Pinedo, A.E., Chen, T., Teles, R., Starr, J.R., Wang, X., Krishnan, K., and Frias-Lopez, J., 2014. Community-wide transcriptome of the oral microbiome in subjects with and without periodontitis. ISME Journal, 8 (8), 1659-1672.

Hua Xie, H.X., Cook, G.S., Costerton, J.W., Bruce, G., Rose, T.M., and Lamont, and R.J., 2000. Intergeneric Communication in Dental Plaque Biofilms.

Ibrahim, S.B., El-sokkary, R.H., and Elhewala, A.A., 2014. Emerging Resistance to Erythromycin and Penicillin among streptococcus pyogenes Isolates in Zagazig. Int.J.Curr.Microbiol.App.Sci, 3 (10), 750-756.

Lateef, B. and Ibrahim, V., 2017. Isolation and Identification Some of microbial causes for dental caries. Tikrit Journal of Pure Science, 22 (9), 9-12.

Marcotte, H. and Lavoie, M.C., 1998. Oral Microbial Ecology and the Role of Salivary Immunoglobulin A. Microbiology and Molecular Biology Reviews, 62 (1), 71-109.

Medicine, G.I., 1984. Book Reviews , Notes , and Listings. Annals of Intern Medicine, 101 (3), 2-8.

Ohara-Nemoto, Y., Haraga, H., Kimura, S., and Nemoto, T.K., 2008. Occurrence of staphylococci in the oral cavities of healthy adults and nasal-oral trafficking of the bacteria. Journal of Medical Microbiology, 57 (1), 95-99.

Patricia M.Tille, 2015. Bailey \& Scott's Diagnostic Microbiology-E-Book.

Petti, S., M, B., GA, M., C, P., and A, P., 2014. High salivary Staphylococcus aureus carriage rate among healthy paedodontic patients.

Press, W. H., Flannery, B. P., and Teukolsky, S. A., 2004. Textbook of clinical cariology. Convergence in the information industries. Telecommunications, broadcasting and data processing 1981-1996.

Turnbull, C.H.S. and D., Dolnicar, S., Chapple, A., Adorno, T., Horkheimer, M., Negus, K., Pickering, M., Leckenby, J., and Li, H., 2004. National Committee for Clinical Laboratory Standards. Why We Need the Journal of Interactive Advertising.

Y Li, Y Ge, D.S., 2007. Genetic profiling of the oral microbiota associated with severe early-childhood caries. 